\title{
JAUME FUSTER, LA FICCIÓ SENSE FRONTERES ${ }^{64}$ \\ Margarida Aritzeta \\ Universitat Rovira i Virgili
}

aume Fuster i Guillemó va néixer a Barcelona el mes de novembre de l'any $1945^{65} \mathrm{i}$ hi va morir el darrer dia de gener de 1998. De formació autodidacta, ${ }^{66}$ profundament culte, bon coneixedor de la gran literatura del seu temps i dels clàssics, alguns dels quals va traduir al català o al castellà, era també un apassionat del cinema, de la literatura popular, dels llibres d'aventures, del còmic... ingredients tots ells que havien format part dels seus anys d'aprenentatge en una Barcelona de postguerra grisa i estreta, que el van forjar com a escriptor. Era també un home afable, bon conversador, hedonista, treballador i amb una forta capacitat de lideratge.

Sovint se l'ha considerat el creador del gènere negre a Catalunya, encara que no va ser pas el primer a publicar novel.la criminal en català a la postguerra. ${ }^{67} \mathrm{I}$ doncs per què ha estat així? Segurament perquè va ser el primer autor de la generació jove que ho va fer amb continuïtat, perquè va crear un tipus de detectiu català (el perdiguer), un argot i un llenguatge propis, perquè va impulsar i dirigir la primera col.lecció de novel.la negra en català, ${ }^{68}$ perquè va buscar la complicitat d'altres autors que s'afegissin

\footnotetext{
${ }^{64}$ Aquest article forma part de les activitats del Grup de Recerca Identitats en la Literatura Catalana (GRILC), reconegut i consolidat per la Generalitat de Catalunya (2014 SGR 755), i del grup de recerca Identitat Nacional i de Gènere a la Literatura Catalana, del Departament de Filologia Catalana de la Universitat Rovira i Virgili.

${ }^{65} \mathrm{Li}$ agradava fer notar que era l'any de la bomba atòmica, o sigui l'any que van esclatar les primeres bombes atomiques sobre Hiroshima i Nagasaki. Recordo que en Pere Calders explicava sovint que ell havia nascut l'any de l'esfondrament del Titànic. Sempre he pensat que en Jaume Fuster deia això de l'any de la bomba en complicitat amb en Calders i amb una enorme ironia.

${ }^{66}$ En acabar el batxillerat es va posar a treballar en una oficina i va decidir que volia ser escriptor.

${ }^{67}$ El varen precedir clarament Rafael Tasis i Manuel de Pedrolo. Manuel de Pedrolo, a més a més, va ser el director de la col-lecció de «La Cua de Palla» d'Edicions 62, que naixia l'any 1963 i que va posar al nostre abast i en català les obres mestres del gènere.

${ }^{68}$ Es tracta de «La Negra», la colllecció de gènere negre amb títols originals d'autors catalans que treu l'editorial La Magrana i que Fuster dirigeix quasi des de la seva creació,
} 
al conreu del gènere, ${ }^{69}$ perquè el va popularitzar en múltiples ambients i mitjans... i potser sobretot perquè els predecessors el van reconèixer com el seu digne hereu.

La primera novel.la negra de Jaume Fuster és en realitat la seva segona novel.la publicada. Porta el títol de De mica en mica s'omple la pica (1972) i de seguida aconsegueix un gran èxit de lectura i de crítica. A partir de 1975, quan apareix l'edició de butxaca, es converteix en lectura recurrent dels instituts de secundària durant molts anys i Carles Benpar en fa una pel.lícula amb el títol de Dinero negro, que s'estrena el $1983 .{ }^{70}$

En aquesta primera novel.la, l'autor ja aconsegueix un repte: que el llenguatge del relat $i$, sobretot, dels personatges, soni real als lectors, encara que en realitat l'estigui inventant a mesura que l'escriu. Recorre a l'argot, a la tradició, remunta fins a Juli Vallmitjana per baratar expressions que encara li puguin servir, però també recorre a la parla del carrer i a la inventiva per posar les bases d'un registre versemblant i actual, modern, que doni cos a un relat popular on apareixen, barrejats, els baixos fons $i$

l'any 1986. Tot i que potser no consta en cap document, segur que la colllecció va ser una iniciativa seva. Recordem que La Magrana, fundada el 1975, era un projecte editorial en què Jaume Fuster hi participava com a soci fundador amb aportació de capital econòmic $\mathrm{i}$ intel.lectual. És a dir, hi va posar diners, però inicialment no cobrava res. La direcció de l'empresa va recaure en Carles-Jordi Guardiola, que va fitxar l'Àlex Broch com a director editorial. Els fundadors de l'editorial eren amics o companys del PSAN i del grup «Trencavel». Recordo perfectament, perquè hi era, el debat que hi va haver a l'entorn de la utilitat que podria reportar l'editorial a la normalització cultural del país.

${ }^{69}$ En Jaume Fuster havia promogut el recull de relats negres del col-lectiu Ofelia Dracs que porta el títol de Negra i consentida (Barcelona 1983), coherent amb el projecte del grup de conrear l'escriptura de gènere i posar a l'abast dels lectors catalans un ampli repertori de textos que engresquessin a llegir. A partir de la colllecció «La Negra» de La Magrana, Jaume Fuster pot oferir als autors del seu entorn la possibilitat de publicar novelles originals i els anima perquè es passin al català si ja conreaven el gènere en castellà, com és el cas d'Andreu Martín, o perquè escriguin novel.les negres en català si abans no ho havien fet, com és el cas de Maria-Antònia Oliver, Antoni Serra, jo mateixa, entre els membres de l'Ofélia Dracs, i força altres noms que s'incorporen de mica en mica a la nòmina de la colllecció.

${ }^{70} \mathrm{El}$ guió del text en castellà, a quatre mans amb en Jaume Fuster, portava per títol El procedimiento, que era el de la traducció de la novel.la. 
les esferes més altes del poder. I fa que la manera com s'expressen resulti creïble.

És una època en què es comentava que no es podria fer novellla policíaca en català perquè els policies parlaven en castellà... i perquè també hi parlaven els delinqüents. Jaume Fuster, partint de la premissa que una ficció és per damunt de tot un assumpte versemblant, és a dir creïble, busca la manera de posar en boca dels personatges, siguin pinxos, bòfies, perdiguers, polítics o andoves de calé llarg, portin pipa a la trinxa o amaguin un raor a la lligacama, visquin en un forat pudent o siguin a la cangrí, una manera de dir que els faci vius als ulls del lector. I ho aconsegueix.

Cap llengua no és mai un entrebanc al geni.

També pretenia fer popular l'expressió novel.la de lladres i serenos per lligar el futur del gènere amb la tradició. Fins que els serenos no només es van acabar, sinó que el jovent ja no va saber qui eren. De vegades encara feia servir aquesta expressió $i$ la defensava amb nostàlgia fins i tot després d'adonar-se que no tenia futur, perquè trobava que era una manera molt nostra d'anomenar el gènere i perquè deia que podia ser una aportació singular al món. Va haver de plegar veles amb els lladres i els serenos, sobretot amb els serenos. La modernitat els va engolir.

Però sí que va aconseguir un tipus de novel.la en què els personatges s'expressessin en un argot que de mica en mica tots vam acabar incorporant $i$ ampliant.

De mica en mica s'omple la pica el va consagrar. En una entrevista, el mateix autor diu al cap dels anys:

El llibre em va permetre encetar aquest gènere que a casa nostra només havia conreat en Rafael Tasis en un període de la postguerra immediata amb tres novel.les, i en Pedrolo amb algunes novel.les, però sobretot amb la direcció i traducció d'alguns títols de La Cua de Palla. A mi em va permetre lligar amb el passat. Vaig fer-ho, va tenir èxit, i d'alguna manera em van saludar com el renovador del gènere. El mateix Pedrolo va esbombar que era el seu hereu en aquest sentit, com a novel.lista de gènere. Des d'aleshores he publicat algunes novel.les més, i sobretot he tingut la satisfacció de veure com aquest camí que jo emprenia el continuaven altres membres de la generació, superant-lo fins i tot. I alguna co- 
sa m'he d'atribuir, perquè com a mínim sóc el primer que ho va fer, i qui és el primer, si més no estableix els paràmetres o enceta camins. ${ }^{71}$

Si l'hem de creure, l'autor afirma que es troba amb el gènere per casualitat, perquè és l'única manera, diu, de poder parlar de la realitat en termes de denúncia en una època de censura. A la mateixa entrevista, explica:

De mica en mica s'omple la pica va néixer com una necessitat d'explicar una història política. És curiós com de vegades et porten les circumstàncies a fer una cosa que potser no pretenies. Jo tenia una informació que m'havia passat un periodista, Joan Anton Benach, un membre de la nova escola de periodistes compromesos que va crear tota una nova concepció del periodisme i que va permetre bona part de la transició. Doncs el Joan Anton Benach em va informar a l'època d'un cas concret, d'una persona important, coneguda, que passava els seus diners a Suïssa i que al mateix temps havia tancat la fabrica al.legant bancarrota. I jo em vaig fer la pregunta: «I com es fa, això de passar tants diners?», perquè no era l'època de l'enginyeria econòmica, com ara, sinó que els diners tenien una presència material; els diners eren bitllets. I aleshores, per contestar-me aquesta pregunta, i probablement per explicar la història d'una corrupció, d'una corrupció lògica en un règim de corrupcions com era el franquisme, sém va acudir que la millor forma de trampejar la censura era a través del gènere negre.

De tota manera, com que les casualitats com aquesta han de tenir algun fonament, l'autor s'afanya a puntualitzar que les seves lectures prèvies, la seva formació, les seves preferències literàries i filmogràfiques, li havien adobat prèviament el terreny per conrear el gènere:

Tinc la gran consciència que va ser una casualitat, casualitat augmentada per les meves lectures de novel.la negra que feia al mercat de Sant Antoni quan era jove, i de les quals el meu pare era un gran lector, i pel cinema que havia vist al barri. Hi ha, doncs, un feed-back de formació, evidentment, però hi ha, sobretot, la voluntat d'explicar una història política que la censura no m'hauria permès si l'hagués explicada amb noms i cognoms, i a més una història periodística.

\footnotetext{
${ }^{71}$ Es tracta d'un fragment de l'entrevista que li vam fer a la URV l'any $1996 \mathrm{amb}$ motiu d'un collloqui sobre la «Generació literària dels 70 », els textos del qual van quedar inèdits. Es pot llegir sencera al blog: http://delllibrealsdits.blogspot.com.es/2013/10/ jaume-fuster-i-lofici-descriure.html
} 
En aquesta primera novel.la negra, el protagonista Enric Vidal, «capaç de tot per una mica de calé», és un brètol. Però no ho és tant, ni de bon tros, com els personatges amb els quals s'embolica. Diners, locals dubtosos, una estafa monumental, tràfic de divises i set morts animen el relat, juntament amb una espectacular persecució en cotxe per les costes de Garraf, de gran tensió narrativa i tall cinematogràfic, que fan les delícies del lector. Al final, la novel.la es resol amb un cert regust d'impotència perquè els poderosos sempre tenen la paella pel mànec i la corrupció no és necessàriament castigada (ni tan sols destorbada) per la justícia oficial. I el lector ha d'acceptar que al capdavall ni tan sols els personatges «bons» no són tan bons com això, o potser ni tan sols no són recomanables, cosa que ocorre sovint a les novel.les de Hammett, Macdonald o Chandler, que Fuster admirava i homenatjava sovint.

Aquesta voluntat d'explicar les entranyes de la corrupció, doncs, s'entronca d'una banda amb el contingut de les lectures i la filmografia de tota una generació d'autors nord-americans que Jaume Fuster admirava (malgrat com es comporten alguns dels seus herois durant el mccarthys$m e)$, i de l'altra banda es fonamenta en el seu compromís personal, la seva militància, que l'empeny a impulsar diversos projectes culturals i de denúncia social i política.

Des d'aquesta primera novel.la negra i al llarg de tota la seva trajectòria literària, l'autor no deixa de conrear el gènere en els seus diversos llenguatges, suports i formats. Això no vol dir que es dediqui només al gènere negre, perquè la seva obra és també molt significativa en altres camps i fins i tot toca registres del que s'ha considerat literatura d'elit. Però alhora defensa contínuament que la literatura de gènere no és un estadi menor de la literatura sinó l'únic estadi possible, perquè no hi ha escriptura sense gènere.

En aquest sentit, en Jaume Fuster batalla contra la crítica contemporània $i$, com a conseqüència, contra la historiografia literària, que tendeix a classificar les obres i els autors seguint una gradació que va des de l'anomenada «alta literatura» (on novel.la, poesia i teatre no tindrien adjectius) fins als gèneres populars (amb els diversos adjectius possibles: negra, d'aventures, rosa, de ciència ficció, etc.). Etiquetar algú com un autor de gènere implica barrar-li el pas a la literatura tout court $i$, per tant, 
als cànons, a les històries de la literatura, als manuals, a la universitat... i l'accés a la lectura d'un públic poc informat que es deixi portar per les etiquetes.

A Jaume Fuster li interessava el conreu de la ficció narrativa sense fronteres ni adjectius. Hi ha bona o mala literatura, deia sovint, hi ha qualitat $i$ geni o no n'hi ha. Una novel.la sempre és d'un gènere $o$ altre, $i$ anteposar-li el gènere al fet de ser novel.la és una fal.làcia. Recordava sovint els seus autors preferits: Graham Greene, Faulkner, Hammett, Chandler... Tots ells tenen, per damunt de cap altra cosa, deia, el geni de contar, la capacitat d'innovar, de subvertir els procediments i tècniques tradicionals de l'escriptura de relats, i una qualitat literària que es manifesta sigui quin sigui el tema o registre que hagin triat a l'hora d'escriure. Quan des de la crítica o des de la historiografia es parla de literatura de gènere, sostenia, es tendeix a considerar que l'únic que interessa d'aquesta mena de relats (que sovint consideren subliteratura) és el vessant argumental o temàtic i no pas la seva vàlua artística, de la qual sovint se suposa que la literatura de gènere n'està mancada.

El que compta d'una novel.la no és el gènere sinó la qualitat, afirmava.

Aquesta va ser una de les grans batalles discursives de Jaume Fuster, que recordava sovint que l'Odissea, La Ilíada, l'Eneida, el Quixot, el Tirant lo Blanc, Madame Bovary, Santuari, El tercer home... per dir només alguns dels títols que citava com a exemple, són relats de gènere. I que és a través del gènere que la novel.la nord-americana incorpora la tècnica del narrador-observador.

Per aquest camí es plantejava quines eren les possibilitats i els recursos dels escriptors del seu temps i les maneres d'arribar als lectors, al públic. No hi ha una sola manera de contar, deia. I afirmava que les fronteres entre els gèneres i els llenguatges són sempre difuses, i que de fet aquestes fronteres difuses de la literatura s'imbriquen amb les de multitud d'altres produccions existents en l'àmbit més general de la cultura. Explorava els llenguatges i els suports de la modernitat. Va ser un dels culpables, amb en Vicent Partal, que els escriptors ens informatitzéssim l'any 1985. Reivindicava l'escriptura electrònica, l'hipertext, els 
jocs dels possibles que faciliten les tecnologies digitals. ${ }^{72}$ Hauria estat un gran impulsor dels Estudis Culturals si hagués entrat més aviat a la Universitat i s'hi hagués dedicat. Hi va accedir tard i de gairell, impartint cursos de guionatge, primer a la URV i després a la Pompeu Fabra. Però el seu camp era la creació i deia molt més en algunes de les seves obres del que altres publicaven en gruixuts o àrids manuals ${ }^{73}$ o del que explicàvem a les aules. Era el més modern dels teòrics de la literatura catalana de l'època, amb perdó dels meus colllegues de professió, sense haver-se

\footnotetext{
${ }^{72}$ Reprodueixo aquest fragment de l'entrevista anteriorment citada, ja que em sembla significatiu al respecte: "[El guionatge] és el procés lògic d'un escriptor de mitjans del s. XX. A partir del moment que John Dos Passos s'interessa pel cinema i formula a Manhattan Transfer l'ull de la càmera com l'objectivització de la realitat, a partir del moment que Joyce dedica un dels capítols sencers de l'Ulisses a la visió cinematogràfica — i Joyce és empresari de cinema, no us n'oblideu-, però sobretot a partir del moment que Hollywood atreu grans escriptors, primer de l'àmbit americà —Faulkner, Hemingway, Scott Fitzgerald, que fracassa-, però també després de l'àmbit europeu a partir dels autors que emigren a causa de la guerra - Bertolt Brecht, per exemple, va ser guionista de Hollywood- no és d'estranyar que l'escriptor de la segona meitat del segle $\mathrm{XX}$, l'escriptor bàsicament narratiu i dramàtic, no l'escriptor de poesia, encara que hi ha excepcions notables, una de les possibilitats que tingui sigui el guionatge, el guionatge per a audiovisual. En el cas català, en cinema és més difícil perquè la indústria de cinema catalana és un desastre. En televisió és més fàcil a partir sobretot de l'existència d'una televisió pública en català. I ha estat la lluita des que va començar TV 3 i ha estat la lluita dels escriptors perquè TV3 deia que no era possible i negava que hi haguessin guionistes fins que un dia va engegar la factoria, és a dir, la producció pròpia, i s'ha demostrar que hi ha guionistes i que a més a més els productes que fan aquests guionistes tenen l'èxit més gran d'audiència. I això està molt bé i això continuarà sent així, espero que durant molt de temps. Hi haurà qui no voldrà començar el camí, hi haurà qui dirà que no serveix per a això; ho trobo perfecte, no és cap mancança; però hi haurà que s'hi dedicarà professionalment, cada vegada més. I fins i tot passarà un fenomen que ja està passant, que és que hi haurà guionistes purs, que no hauran hagut de passar abans per l'escriptura narrativa o de ficció, o per l'escriptura dramàtica, que entraran directament en el món del guionatge. I em sembla molt bé, no hi ha cap problema. I diré més: probablement el guionatge audiovisual ben aviat serà obsolet, i el que haurem d'anar a redactar com a guions seran més aviat llenguatges cibernètics, és a dir, hipertextos o CDs. Tinc la sensació que el camí anirà per aquí, perquè d'alguna manera l'audiovisual, tal com l'entenem ara, s'està acabant».

${ }^{73}$ El semiòleg Iuri Lotman (1970) manifestava, en aquest sentit, que és molt més clar i profund un conte de Txèkhov que un manual gruixut de psicologia.
} 
dedicat mai a la teoria. Qualsevol que hagués conversat llargament amb ell sobre els camins i les eines de la creació en pot ser testimoni.

Admirador d'aquells grans escriptors que havien escrit per a Hollywood, com Bertold Brecht, James Joyce, Graham Greene, John Dos Passos, William Faulkner, i tants d'altres, Jaume Fuster escriu en equip guions per a la ràdio, el cinema i la televisió (alguns dels seus col-laboradors més assidus van ser Guillem-Jordi Graells, Jaume Cabré, Vicenç Villatoro, Antoni Verdaguer). Majoritàriament de gènere negre. De vegades, en primer terme hi ha el llibre, que es converteix en pel.lícula, representació o serial. Però en altres ocasions és a la inversa: el relat neix amb clara vocació de ser espectacle, i des del cinema o el teatre o el concurs televisiu ${ }^{74}$ s'acaba arribant a la versió per al llibre, de la mateixa manera que del recull de relats solts publicats també s'arriba al volum.

Capítols singulars en les aportacions de Jaume Fuster a la novel.la negra catalana són també els seus personatges i els homenatges literaris que introdueix als seus relats, a manera de joc intertextual. Aquests homenatges, que de vegades es concreten en el préstec d'un nom o la paròdia d'un títol, lliguen la literatura catalana amb les altres literatures i aporten al lector català la familiaritat d'uns personatges, uns autors $i$ unes obres que són patrimoni del món. Ens és fàcil resseguir-ho, i sobretot entendrén els motius, si tenim en compte la seva Poètica personal, que explicita en una obra de creació magnífica i molt més illlustrativa que cap manual. Es tracta de Tarda, sessió contínua, 3,45 (1976).

Anem a pams.

A la novel.la De mica en mica s'omple la pica apareix el personatge de l'Enric Vidal, «un brètol capaç de tot per una mica de calé», segons la definició que fa d'ell mateix. Aquest personatge té un bon recorregut al llarg de la producció literària de Jaume Fuster.

El trobem a La matèria dels somnis ${ }^{75}$, un recull de relats escrits al llarg de prop de quinze anys i aplegats finalment en un volum el 1986. En aquests relats, l'autor introdueix noms i indrets del món real i els barreja

\footnotetext{
${ }^{74}$ És el cas de Les cartes d'Hèrcules Poirot. Les claus de vidre neixen com a text i acaben essent també guió televisiu i concurs.

${ }^{75}$ Títol que fa una referència clara a la novel.la El falcó maltès, de Dashiell Hammett.
} 
amb llocs i personatges dels mons literaris i cinematogràfics, de manera que tots, reals $\mathrm{i}$ imaginaris, conviuen en un univers nou, on arriben a dialogar amb l'autor. Aquesta és una tècnica que també havia usat a Tarda, sessió contínua, 3,45, i que representa un homenatge molt clar a Pirandello. ${ }^{76}$

Trobem també l'Enric Vidal demanant ajut a la jove Ofèlia Dracs en el recull Negra i Consentida (1983), en un conte titulat Ofélia a les tres, que era el «seu», encara que en el colllectiu els autors no signàvem els relats.

A La corona valenciana (1982), l'Enric Vidal es veu embolicat en el robatori de les joies de la Mare de Déu d'Elx al santuari de Santa Maria, on es representa El Misteri d'Elx. I com que no es resigna a compartir el botí amb els cràpules que l'han perpetrat, protagonitza una llarga peripècia amb molta sang i fetge $\mathrm{i}$ amb força detalls de gastronomia, de la qual en Jaume Fuster era un bon amant, com a cuiner i com a gourmet, pel

\footnotetext{
${ }^{76}$ Afirmo que és Pirandello perquè n'havíem parlat, encara que no sigui l'únic autor que introdueix la ficció de dialogar amb els seus personatges. De fet, a Jaume Fuster, que també havia fet teatre amb el grup El Camaleó, li interessaven els bucles narratius, que fan que la narració es replegui sobre ella mateixa, i citava els exemples d'Homer o de Shakespeare, entre altres, encara que jo insistia a parlar-li de Borges. A l'entrevista abans esmentada menciona les seves incursions al teatre: «El món del teatre va tenir molta importància per a la generació literària dels 70. A l'estrena d'El retaule del flautista, per exemple, no a l'estrena del teatre Capsa, amb el Pau Garsaball, és a dir, amb companyia estable, sinó a l'estrena de teatre independent que van fer conjuntament El Camaleó i el GTI, dirigida per Francesc Nel.lo, hi havia el Jordi Teixidor com a actor, la M. Antònia Oliver com a actriu, l'Andreu Martín com a actor, i va assajar amb nosaltres, encara que no va arribar a estrenar, la Montserrat Roig. Pel que fa a les Preguntes $i$ respostes de Francesc Layret, advocat dels obrers de Catalunya, que va muntar la M. Aurèlia Capmany amb la colllaboració de Xavier Romeu, no la vaig estrenar al principi, però com que van retirar el passaport a algun dels actors que la feien, em vaig incorporar al muntatge per anar a París a representar-la; la vam interpretar el Jordi Teixidor, el Feliu Formosa, jo mateix, el Joan Rendé i, encara, la Maria Plans i el Jesús Saldaña, em sembla, i el Ramon Teixidor. D'escriptors, doncs, érem el Jordi Teixidor, el Feliu Formosa, el Joan Rendé i jo. Fixeu-vos, doncs, la presència d'escriptors en coses teatrals. I si ens remuntem al GTI, on jo no havia actuat, hi havia com a actriu la Montserrat Roig i fins i tot el Josep M. Benet i Jornet».
} 
País Valencià, per terra i per mar, fins a Eivissa, de costat amb una tal Marlowe, nom que evoca un altre dels seus homenatges literaris. ${ }^{77}$

Un altre dels seus personatges recurrents és el perdiguer Lluís Arquer, que l'autor manté al llarg de diverses novel-les, jocs de ficció i relats. És facil adonar-se que aquest detectiu és l'homònim de Lew Archer, el detectiu de Ross Macdonald. En Lluís Arquer apareix a Les claus de vidre $(1984),{ }^{78}$ en una clara simbiosi d'homenatges creuats a Hammett i Macdonald, i reapareix a Sota el signe de sagitari (1986), a Quan traslladeu el meu fèretre (1987), Vida de gos i altres claus de vidre (1989), i a Anna i el detectiu, una novel.la juvenil que es publica el 1993.

El primer dels homenatges literaris explícits que trobem a l'obra de Fuster és la dedicatòria que inclou a De mica en mica s'omple la pica, on diu que Dashiell Hammett és per a ell el millor autor del gènere. No sé si el fet d'incloure a la mateixa novel.la un personatge secundari que s'anomena Isabelle Dupin es pot comptar com a homenatge a Edgar Allan Poe, considerat el creador del gènere policíac, pel seu personatge Auguste Dupin. En tot cas, queda dit: amb Jaume Fuster cap coincidència de nom no és casualitat.

A partir d'aquesta primera obra, l'autor cita, parodia, dialoga, reescriu... agafa noms d'autors i personatges, agafa títols i els adapta, els tradueix, els canvia, sempre mostrant veladament què hi ha al darrere per fer-nos notar que hi juga, que com a autor forma part d'aquest món de ficcions i d'escriptors i que com a cultura i com a lectors també en formem part.

L'homenatge a Hammett es torna a fer explícit a Tarda, sessió contínua, 3,45, continua a La matèria dels somnis amb una clara referència a

\footnotetext{
${ }^{77}$ El detectiu Philip Marlowe, de Raymond Chandler.

${ }^{78}$ Les claus de vidre és un llibre de disset relats que va servir com a base per al guió de tretze enigmes emesos l'any 1985 a TV3 en forma de concurs policíac. Els relats es plantegen com un joc d'enginy que desafia el públic a resoldre un enigma triant alguna de les propostes per resoldre el cas. El títol fa una clara referència a la magistral novel.la de Hammett La clau de vidre, que obria la collecció de novel.la negra de «La Cua de Palla», d'edicions 62, que aleshores dirigia Manuel de Pedrolo.
} 
El falcó maltès, i es veu encara confirmat, jugant sempre amb els títols, en el recull Les claus de vidre.

Aturem-nos un moment a Tarda, sessió contínua, 3,45.

La novel.la comença quan en Jaume, un escriptor adult, contrafigura de l'autor, passa per davant d'un cinema de barri que estan a punt d'enderrocar. Immediatament li vénen a la memòria les tardes de diumenge que hi va passar en la seva infantesa i adolescència, durant els seus anys de creixement. I a manera de retorn a aquell nen que un dia va ser, li reescriu el somni (la pellícula) que li hauria agradat veure. Hi aporta tot el que ha vist, ha après, ha llegit, els llibres i les pel-lícules, la sordidesa de la vida, la calidesa del desig.

No es tracta pròpiament d'una novel.la de gènere negre. Si hi haguéssim de posar un adjectiu diríem que és una obra mestra $i$, insistint, diríem que és una novel.la d'aprenentatge, un bildungsroman. Però a través d'aquesta novel.la es juga amb multitud de referents que són patrimoni de la millor literatura i filmografia negres de l'època. Per començar, el títol de la pel.lícula que oferirà l'escriptor a la memòria del nen és Collita de sang, que evoca de manera transparent la Collita roja de Dashiell Hammett.

El nen, assegut de nou a la butaca del cine de barri gràcies a un llarg flash-back, segueix endins de la ficció el seu actor preferit (Humphrey Bogart), s'hi identifica i projecta en ell els desigs del seu viure quotidià per l'únic camí que li permet aquella Barcelona encotillada i grisa dels anys cinquanta, que és el camí de la fantasia. El lector es podrà adonar de com connecten el mite i la vida quotidiana, la literatura i el cinema, el text i el desig. També podrà veure que les il.lusions dels herois, els del cinema i els que a la novellla caminen pel carrer, coincideixen amb els desigs i les vivències de tota una generació de lectors i espectadors que es varen fer grans a la Barcelona d'entre els anys 50 i 70 . I també s'adonarà que els mons d'aquells protagonistes formen part de l'imaginari de qualsevol lector de qualsevol edat que en un moment o altre s'ha sentit seduït per la màgia del cinema o de la ficció literària.

Collita de sang és una reescriptura de Collita roja. Inclou fragments textuals de la traducció al català del text de Hammett, que acabava d'aparèixer a «La Cua de Palla» en el moment que Jaume Fuster redacta- 
va la seva novel.la. L'argument, però, s'hi cenyeix només en part, perquè l'autor hi canvia el final $i$, alhora, hi imbrica altres referents literaris $i$ cinematogràfics que li serveixen per fer visibles les seves preferències i els seus mestratges. Mestratges que són els de tota una generació i que la història ha situat en l'estadi del mite.

D'aquesta manera, a la ficció que imagina l'escriptor adult perquè el nen la vegi en forma de pel-lícula, hi trobem junts i amb els seus noms reals, però en els seus papers, els actors Humphrey Bogart, Laureen Bacall, Mary Astor, o el mateix John Wayne (que fa de xèrif antipàtic), en un repartiment insòlit que mai no es va produir en cap film real, $i$ on no s'oblida la citació de la matèria dels somnis que ens recorda El falcó maltès i ens retorna Shakespeare, ni el paper de «l'home que mou el somni», que es pot dir Huston, Hawks, Walsh o Cromwell, qualsevol dels grans directors.

Trobem, al costat d'aquests noms mítics de Hollywood, i al mateix nivell narratiu, retalls d'altres ficcions: un gàngster anomenat De Corsia que regenta un local que porta el nom de "Casablanca», on hi ha un negre que toca el piano... Però no és només Casablanca la que s'encreua en l'imaginari del nen que va cada diumenge al cinema, ni són només la resta de les pel-lícules de Bogart. A Collita de sang hi concorren els materials mitificats dels grans llibres que el nen anirà llegint al llarg dels anys, fins a convertir-se en el Jaume escriptor.

Així, hi apareix el mateix polític Greenstreet, gras i arrodonit, que podem trobar a El falcó maltès (Hammett). Noms propis i topònims que formen part de l'imaginari de Faulkner: Temple i Popeye (Santuari), Yoknapatawpha; un lloc anomenat Chandlertown (en realitat un homenatge creuat a Chandler i Faulkner, quan situa aquesta població a Yoknapatawpha); Jackson, a l'estat de Jefferson (Faulkner), que elegeix com l'espai de la corrupció i de la intriga política contra els humils (un altre cop Santuari), i que alterna amb el Poisonville de Hammett (Collita roja), on Elihu Willson, que a la pel-lícula ja és mort, encara tallava el bacallà; hi trobem en Terry Lennox bevent gimlets, i Sam Spade, que treballa per a la Continental (Hammett), actua directament, alternant el nom de Spade amb el de Bogart. 
En realitat la ciutat minaire i l'ambient sindical de Collita de sang s'assemblen prou als de L'agent confidencial de Graham Greene, un altre dels autors preferits de Jaume Fuster, però potser són apreciacions personals meves. També apareixen en la memòria de l'escriptor l'Ethel Barrymore, el detectiu Philip Marlowe (Chandler) i els personatges i paisatges de La gran dormida (Chandler), entre d'altres.

Realment, és una novel.la interessantíssima, genial des del punt de vista de la tècnica narrativa i la poètica de l'escriptura de ficcions, que era perfectament accessible al lector mitjà de l'època però que avui requereix d’un públic una mica llegit. I això per una raó molt senzilla: les grans obres mestres del cinema les havia vistes tothom i les de la literatura s'havien anat posant a l'abast dels lectors, traduïdes al català, en les colleccions d'Edicions 62 i Proa. Tots les havíem llegides i sabíem identificar els jocs d'intertextualitat.

El lector actual no especialitzat també pot tenir una lectura plaent del llibre, encara que potser només en traurà la part anecdòtica, que no és poc, perquè podrà seguir amb emoció l'aventura d'aprenentatge d'un vailet que ha de créixer en una ciutat estreta de mires i on les úniques escapades que se li ofereixen són les ficcions, el cinema i la literatura. I el rerefons argumental d'un relat negre fet a la mida d'un personatge que indulta alguns dels seus herois encara que siguin dolents.

El lector interessat a buscar-hi el rerefons documental, i fins i tot la construcció autobiogràfica de Fuster, també hi trobarà els seus al.licients, perquè és a partir d'aquesta novel.la que l'escriptor comença a construir la seva imatge pública. ${ }^{79}$

\footnotetext{
${ }^{79}$ Jaume Fuster deia que, quan un escriptor parla d'ell mateix, també fa literatura i, en construir la seva imatge, està influint en la manera com l'han de veure els altres. Així va ser com va decidir que la seva personalitat se sostenia en tres pilars: la llengua, els orígens menestrals i la Barcelona de barri. Alguns d’aquests elements són els que explora la novel.la Tarda, sessió contínua, 3,45. Fuster en parlava a l'entrevista esmentada pàgines enrere: «El cinema de barri, el cinema, l'audiovisual en general, té una importància cabdal en la meva formació literària, i diria que fins i tot humana, fins i tot política. I el còmic, el «tebeo» com en dèiem aleshores, també. Però jo em permetria dir que en aquest període de formació, que no va exactament del dia que va morir Marilyn al dia que va morir Kennedy sinó que va des de la bomba atòmica, que és quan jo vaig néixer, el 1945, fins aproximadament el maig del 68, que és quan jo vaig fer la mili, hi ha tres
} 
En Jaume Fuster no era només un home fascinat pel mon americà. També li interessaven les novel.les criminals europees i era un bon lector de les franceses i les angleses. N'és una bona prova el personatge d'Hèrcules Poirot, d'Àgatha Christie, que li serveix per crear Les cartes d'Hèrcules Poirot, aparegudes com a llibre l'any 1983, concebudes inicialment com a guió televisiu i finalment escrites com a teatre per a la televisió. Darrerament va encetar encara un joc detectivesc a quatre mans amb el físic Antoni Lloret: Micmac, novel.la apareguda el 1993, que conjuga el gènere negre amb la tècnica epistolar (em consta que s'escrivien les cartes per fer avançar el llibre), i encara amb el món de la recerca científica, d'on prové Lloret.

elements de molta importància: un és la Cerdanya, mítica, però vinculada a la llengua; l'altre és l'origen, l'origen de classe, i el tercer la ciutat de Barcelona. En el cas de la Cerdanya, per a mi representa els lligams amb la llengua [... $]$ Si vam parlar en català $i$ vam escriure i continuem escrivint en català és per alguna mena de miracle que de tant en tant produeixen els pobles vençuts. Jo trobaria aquest miracle en les arrels aquestes pageses, és a dir, en la Cerdanya, on la gent parlava en català no perquè tingués actituds fèrries de resistència, simplement perquè no sabia parlar castellà. La menestralia —en reivindico el nom: proletariat és un terme polític, classe obrera és un terme econòmic; en canvi menestralia ajunta la política i l'economia i al mateix temps li dóna un to de sentiment-, la menestralia, doncs, a la qual pertanyo, és un producte autèntic, sui generis, de Barcelona format per gent normalment vinguda de la mateixa Catalunya, però de la Catalunya profunda - els meus pares, en el meu cas, de la Catalunya «de cap al nord» del Pirineu, pel que fa a la part materna-, treballadors, no forçosament treballadors de fàbrica però treballadors amb sou de treballadors de fàbrica de l'època, sense possibilitats de formació universitària. En aquest sentit, jo vaig començar a treballar als catorze anys, i això crec que és important. El tercer element d'aquesta formació entre cultural i sentimental ens porta a la ciutat de Barcelona, la Barcelona de barri, no la Barcelona de l'Eixample sinó la Barcelona de barri que el Terenci i jo coneixem amb molts pocs anys de diferència. Tots dos naixem a $150 \mathrm{~m}$ de distància en línia recta, entre el carrer de Ponent on creix ell i el carrer de Tallers on neixo jo. Vázquez Montalbán neix a 150 m més enllà, a la plaça del Padró. Però és que el Josep M. Benet i Jornet neix a 150 m més enllà, a la Ronda. Aquesta mena de barri d'aquesta Barcelona antiga, que és a la frontera de les muralles, és molt important per entendre aquesta formació meva. Per tant, la menestralia com a classe, la Cerdanya com a llengua i com a arrel, la ciutat de Barcelona una mica com a alambí on es genera tot. I cinema, i el còmic. Però també literatura». 


\section{Revista de Filologia}

Però un dels grans mèrits de Jaume Fuster va ser la popularització del gènere, el fet de posar-lo a l'abast de la població, sense estrafer-lo ni banalitzar-lo, a través dels seus molts diversos registres i canals comunicatius. Va aconseguir grans audiències a la televisió amb uns episodis que preparava a quatre mans amb en Guillem-Jordi Graells, va omplir setmana rere setmana el teatre Victòria per assistir a la resolució dels seus enigmes, que es transmetien per televisió, va mobilitzar actors i personatges, va entrar a l'ensenyament i va posar detectius a les lectures de Secundària. I sempre mantenint el rigor de l'obra ben feta, l'exigència, el nivell. $\mathrm{Va}$ engrescar els escriptors a escriure $\mathrm{i}$ els lectors a buscar les seves novel-les.

$\mathrm{Li}$ agradaria veure que el gènere torna a tenir sang a casa nostra.

BIBLIOGRAFIA

ARITZETA, Margarida (1998): «Jaume Fuster, el compromís amb la literatura», Serra d'Or, núm. 461 (maig), p. 14-18.

BALLESTER, Josep (1995): «Jaume Fuster, "La Guàrdia del rei"», Serra d’Or, núm. 423 (març), p. 54-55.

BONADA, Lluís (1991): «Jaume Fuster: "A partir d'ara, les meves novel-les estaran marcades per la lectura del Tirant"» [Entrevista]. El Temps, núm. 381 (desembre), p. 65.

CANAL, Jordi i Àlex MARTÍN (2011): La cua de palla: retrat en groc $i$ negre, Barcelona, Editorial Alrevés.

CARAlTÓ, Xavier (1989): «Jaume Fuster», Avui Cultura, 2 de desembre, p. VI.

Delgado, Josep Francesc (1983): «Les cartes d'Hèrcules Poirot', per Jaume Fuster», Serra d'Or, núm. 290 (novembre), p. 55.

DIVERSOS AUTORS (1999): Jaume Fuster [Homenatge]. Barcelona, Ed. 62.

FEBRÉS, Xavier (1985): (Transcriptor), Diälegs a Barcelona (Manuel Vázquez Montalbán/Jaume Fuster). Barcelona: Laia.

GRAELLS, Guillem Jordi (1998): «Jaume Fuster, narrador i prestidigitador», Serra d’Or. Barcelona, núm. 461 (maig), p. 19-21. 
GuILlamon, Julià (1985): «Jaume Fuster: Literatura i cinema», Avui, (8 setembre)

LLEONART, Aitana (2003): «De mica en mica s'omple la pica», Avui, (20 setembre).

LlORCA, Vicenç (1998): «Petit retrat de Jaume Fuster», Serra d'Or, núm. 461 (maig) p. 12-13.

MARTín, Àlex i Jordi CANAL (2013): «Cap a on va, "La Negra"? La desfeta d'una experiència literària», Revista de Catalunya, núm. 281, p. 165-172.

MARTÍN ESCRIBÀ, Àlex (2004): La narrativa negra catalana contemporánea: Jaume Fuster. Treball de Grau. Universitat de Salamanca.

- (2005): «Jaume Fuster, una vida en negre», Serra d’Or, núm. 547-548 (juliol-agost), p. 71-74.

- (2007): «Enric Vidal y Jaume Fuster: un investigador y un autor caídos en el olvido», en Àlex MARTíN I Javier SÁNCHEZ (eds.), Informe confidencial: la figura del detective en el género negro, Difácil.

- (2010): «Jaume Fuster, el jugador compulsiu», Serra d’Or, Núm. 611 (novembre), p. 47-49.

MunNÉ-JORDÀ, Antoni (1998): «L'altra literatura de Jaume Fuster», Serra d'Or, núm. 461 (maig), p. 22-24.

NADAL, Marta (1992): «Jaume Fuster, una literatura cinematogràfica», Serra d'Or, núm. 386 (febrer).

ORIOL I GIRALT, Joan (1988): «Jaume Fuster, "Per quan vingui un altre juny”», Revista de Catalunya, núm. 20 (juny), p. 158-159.

- (1993): «Jaume Fuster per a lectors joves», El Temps. núm. 481 (6 de setembre), p. 79.

PARTAL, Vicent. (2013): «Jaume Fuster», Avui (31 de gener), p.2.

PIERA, Josep. (1982): «Jaume Fuster: La corona valenciana», L'Espill, núm. 15, p. 159-160.

RENDÉ MASDEU, Joan. (1993): «Jaume Fuster, entre el gènere i l'al-legoria», Serra d'Or, núm. 408 (desembre), p. 15-17.

RiERA, Ignasi (2007): «Jaume Fuster», Avui (31 de gener), p. 24. 
SOLÀ I CORTASSA, Joan. (1998): A vui Cultura (26 de febrer; 5 de març), p. $7 ; 6$.

TEIXIDOR, Emili. (1991): «Jaume Fuster, "De mica en mica s'omple la pica"», Catalan Writing, Barcelona, núm. 7 (Setembre), p. 84-85.

EN INTERNET:

PAGÈS, ROSA (1996).

HTTP://DELLLIBREALSDITS.BLOGSPOT.COM.ES/2013/10/ JAUMEFUSTER-I-LOFICI-DESCRIURE.HTML. 